\title{
TÜRK MEDENÎ KANUNUNDA MIRAS HUKUKUNUN ESASLARI
}

Prof. Dr. \$akir BERKI

Etüdde, miras trukukiyle ilgili büitün bahisler kanundaki sistematilk tâkip edilmek suretiyle incelenecek. tir. Aşağı yukarı şerhlerdeki madide sırasına ehemmiyet verilecek ve bu suretle hiç bir madde ve hattâ fikrası ihmal edilmemeye dikkat olunacaktır.

§ 1. MilRASCILAR. MD: $439-448$

\section{I - Füru. Md. 439}

Ölenin birinci derece mirasclarn çocuklar1, bunlarnn evvel ölmüs olmaları halinde torunlan ilh... dir. Her türlü füruun mirascı olabilmesi için ölenle arasmda sahih veya gayrısahih nesep münasebetinin bulunması lâzımdır. Fürûun ölene karşı nesebi, miras açlldiktan, hatta taksim olunduktan sonra kurulsa ve meselâ nesebi hâkim hükmüi ile tashih edilse nesebi tashih edilen füru meşru fürû olarak hak iddia eder. Zira nesebin tashihi kısmen makabline şâmildir'; Keza nesepsiz gayrı meşru çocư̆un ölen babasına karşı nesebi hâkim hükmï ile miras açıldıktan sonra kurulmuş olsa, keza bu fürû da terekede gayrı sahih nesepli çocuk sıfatiyle hak iddia edebilir. Zira gayrı sahih nesebin kurulması, münakaşa konusu olmuş ise de, makabline teşmil edilmek lâzumdır; Füruun hepsi meşru ise, müsavat üzre hisse alırlar. Aralarinda gayrı sahih nesepli fürû varsa, hissesi meşru çocuk hissesinin yarısı nispetindedir ${ }^{2}$. Evlâtllk da mevcut ise, kaideten meşru fürû hissesi alır; istisnaen ya tespet edilen hisseyi alır veya hiç hisse alamaz ${ }^{3}$.

\footnotetext{
${ }^{1} \mathrm{Bu}$ hususda yazının ikinci kısmına bakımı.

2443 üncï madde izahmra baknniz.

3447 inci madde izahma bakmtz.
} 


\section{II - Ana ve Baba Md : 440}

Ölenin füruu yoksa, ana ve babası müsavat üzre mirascidrr. Ana, baba murisden evvel ölmüs iseler, bunlarn füruu yani murisin kardeşleri ilh... halefiyet suretiyle mirascıdır. Ana veya baba tarafında hiç mirasci yokssa, yani murisin meselâ babası evvel ölmüs ve füruu da yoksa, bunlara geçecek olan pay hayatta kalan anaya intikal eder, Kayd edelimki, evvel ölen ana veya babanın füruu bulunmasa ve kendilerine geçecek pay hakkında mansup mirascı naspetmiş olsalar, bunlar mirasa gelemezler; zira mansup mirascılık ancak bir şahsın kendi terekesi üzerinde kabul edilebilen bir mirascliktır. Evvel ölen ana babanın evlâtlığı halefiyetde taksime iştirak edemez. Meselâ ana evvel ölse, bir meșru çocuk bir de evlâtlık ${ }^{4}$ bıraksa anaya ait hisse meşru çocư̆ga ait olur. Evvel ölen ananın hakiki füruu olmasa, iki evlâtlığı ${ }^{\mathrm{s}}$ bulunsa, anaya ait pay, murisin hayatta olan babasının olur, evlâthklar bir şey alamaz.

\section{III - Büyük ana baba (ananin ana babast, babanin ana ba- basi) Md : 441}

Ikinci derecede hiç mirascı bulunmadığı zaman, mirascı murisin ana ve baba tarafindan nine ve dedeleridir. Yani bu halde terekeyi dört kişi müsavat üzere taksim ederler. Bunlardan biri murisden evvel ölmüiş ise, payı füruuna geçer; ana tarafından baba ölse ve iki oğlu (murisin iki dayısı) hayatta bulunsa, murisin ana tarafından dedesine düssecek olan pay bunlara geçer. Bunlar da olmayıp füruu olsa onlara, yani dayı çocuklarnna ilh... geçer ${ }^{6}$ Evvel ölen dede veya ninenin füruu olmasa, hisse, aynı tarafdaki nine veya dedeye geçer; murisin ana tarafindan dedesi veya füruu olmasa, dedeye düşecek hisse baba tarafmdan nineye, bu da evvel ölmüs, füru burakmıs ise onlara ait olur. Ana tarafindan nine ve dede ve füru mevcut değilse, bu tarafa geçecek olan pay, baba tarafindan nine ve dedeye veya bunlar evvel ölmüș ise, amca, halalara veya bunların çocuklarına ilh... e intikkal eder.

${ }^{4}$ Meşru çocukla evlâtlık içtima edebilir. Şakir Berki, Türk. M. Kanunun'da çocukların mirası» A.H.F. Dergisi. c. XXII, sa: 264.

${ }^{5}$ Evlâtlı̆̆ı bulunan bir kimse müteaddit evlâtllklar edinebileceği gibi, hị̧ evlâtlığı olmayan şahıs aynı anda iki veya daha ziyade kimseyi evlâd edinebilir.

' Her türlii halefiyetde mutlaka halefin ana baba bir füra olması icap etmez. 


\section{IV - Büyükbaba ve analarm baba ve analar. Md : 442}

Müteveffanin ana ve baba tarafindan nine ve dedeleri ve bunların füruu bulunmazsa, kanunî mirascllar nine ve dedelerin ana ve babalarıdır. Ancak bunlamn mirascılığı intifa hakkına münhasundır; rakabeye sahip olamazlar. Bu suretle kanun «bir derecede mirascı varken diğer derecedekilerin mirascı olamayacağı" esasını istisnaya tâbi tutmuștur. Intifa hakkı sahibi mirasclları mevcut i.ken, muris terekesinin tamamında üçüncï bir șahsı mirascı nasp edebilir. Lâkin mansup mirascı intifa hakkına sahip mirascların hayatı middetince, terekeden intifa ${ }^{7}$ edemez. Mansup mirascı bu. lunmadığ takdirde terekenin rakabesi en son kanunî mirascı olan devlete ait olur. İşte bu halde dereceleri ayr olan iki kanunî mirascı içtima etmiş olur: Döndiünoui derece mirascisı olan büyü̈k ana babaların ana babaları ve en son derecedeki devlet.

Müteveffanın hayatta kalan eşi mevcut oldukça, 442. madde kabili tatbik olamaz; yani müiteveffanm büyüik ana babalarının ana ve babalar, ne rakabe, ne intifa mirascisi olarak mirasa gelemezler. Zira 444. madde buna mânidir. Bu madde șerhine baikını.

Hayatta kalan eș mevcut oldukça hazine de mirasa gelemez.

Intifa mirascısı, yani büyük ana ve babaların ana ve babaları, müteveffadan evvel ölmüs ise, kardeşler, yani müteveffanın büyük amca, hala, dayı veya teyzeleri intifa hakkına tevarüs ederler.

\section{V - Sahih olmayan nesebde miras. Md : 443}

Evlilik haricinde doğan her çocuk ana cihetinden aynen meşru çoouk gibi mirascıdır. Baba cihetinden meşru çocuğun hissesinin yarısı nispetinde hisse alır. Bu taksim, meşru çocuk ile içtima haline mahsustur. Gayrısahih nesepli çocuklar mirasda müstakil kalsa, baba cihetinden aynen meşru çocuk gibi tereke aralarında müsavat üzre taksim edilir. Evlilikk dışında doğan çocuğun babasına mirascı olabilmesi için tanıma veya hâkim hükmü ile gayn sahỉh nesebinin babasına karşı kurulmuş olması lâzımdır.

Nesebi gayrı sahih çocuk, ana veya babasından evvel ölse, fü. ruu gayrtsahih nesepli olsa dahi, halefiyet suretiyle mirasa gelir, yani gayri sahih nesepli bir torun dedesinin mirasına halefiyet suretiyle gelebilir. Md. 443/2.

${ }^{7}$ Kanum intifa demiş, şumulünï göstermemiş olduğundan, intifa (M. K. Md: 717) mucibince kullanma ve semerelerden faydalanmaya şâmildir. 


\section{VI - Eşin mirascilığı. Md : 444}

Eş hısım değildir, akrabanın en yakınıdır. Binnetice derece mirascisı olmayıp her derecede mirascidir:

1. Müstakil ise, yani müteveffanın (ölen eşin) füruu, ana ba. bast veya bunların füruu, yahut büyuik ana babaları ile içtima etmemiş ise, mirasın tamamına sahip olur. Hazine eș ile içtima etmez ${ }^{8}$.

2. Ölen "karı veya kocanın çocư̆u" veya torunlan hayatta ise, hayatta kalan eș, dilerse terekenin dörtde birinde rakabe tevarüsiinü ister, bu halde iterekenin dörtte birinin mâliki olur; dilerse bunun yerine terekenin yarısinda intifa verasetini kabul eder. Hayatta kalan es, birden ziyade ise ${ }^{10}$ ve hepsi mülkiyet hakkın tercih etmiș iseler, terekenin dörtte biri aralannda eşit olarak taksim olunur. Fakat bir kısmı intifa, bir kısımı mülkiyeti seçmiş iseler, Yargıtayın aksi içtihadına rağmen, zannımızca mülkiyet veraseti asıl, intifa mirascilığ ona nazaran istisna olduğundan, mülkiyet seçenin reyine itibar ederek taksim icra etmek uygun olur. Zira seçim bölünemez; yani seçim ile ya mülkiyet veya intifa veraseti icra olunur. Bu seçim hakkının icabıdır."

Hayatta kalan eş, ölen eşinin îkinci dereoe mirascılarn ile içtima ederse, mirasdan dörtte birinin müllkiyeti ile, yarısinın intifa hakkma sahip olur. Bu halde seçim hakkı olmadığından yargıtay kararınt zikre lïzum yoktur.

Ölen eşin dede ve nineleri veya bunların fürư, (ölen eșin amca, hala, dayı, teyzeleri veya fürularryle) içtima eden eș, terekenin yarısına sahip olur ve döntte birinde intifa trakkı iktisap eder. Bu. radada seçim yoktur.

Hayatta kalan eş, ölen eşinin büyüik ana babasının ana babala. rn ile içtima etse, terekenin tamamına sahip olur. Fakat, 442/2 deki hükü̈m halefiyete dair özel bir hüküm olduğundan, eşle içtima eden murisin (ölen eş) büiyük ana ve babasıntn ana babalarına, tereke-

\footnotetext{
\& Islâm miras sisteminde hazine eş ile beraber mirasa gelebilirdi.

${ }^{9}$ Çocuğun ana baba bir çocuk olması icap etmez. Hayatda kalan es övey çocukla içtima edebilir.

కo Medenî Kanununun Md. 124/2. mutlak butlanla bâtıl olan evlilik hakkın. da butlan Kararı alınmadıkça sahih evlilił̣̌in bütün hüktüm ve neticelerini doğuracağı yazılı olduğuna göre, ikinci evlenme hakkında butlan kararı verilmeden evvel birden ziyade evli karı veya koca ölse hal böyle olur.

"Şakir Berki "Miras Hukuku», Ank, 1959, sa : 9.
} 
nin yarısında intifa hakkı tanımak icap edeceği fikrindeyiz. Eş, bunlarnn kardeşleri ile içtima etse, 442/3 mucibince bunlar da intifa hakkına mirascı olurlar ${ }^{12}$. Bunlar da bulunmadiğı takdirde, hayatta kalan eş, terekenin tamamma tam mâlik olarak vâris olur. Hazine eşle kanunî mirascı sıfatıyle içtima edemez. Lâkin gerek hazine, gerek sâir hüikmî ve hakikî şahıslar mirasda kanunen müstakil ikalan eşle mansup mirascı sıfatıyle içtima edebilir. Ölen eș, hayatta kalan eșin mahfuz hissesini ${ }^{13}$ aşmamak ùzere bunlardan birini mirasci nasp etse ${ }^{14}$, hal böyledir ${ }^{15}$.

Son olarak kayd edelim ki hayatta kalan eşle, ölen eşin gaynsahih nesepli çocuğu içtima etse, çocuk meşru çocuk gibi mirascl olur; yani 444/1 deki hükümden istifade eder. Ölen eşin hem meşrû, hem gayrı sahih nesepli çocuğu eşle içtima etse çocuklar ikili birli taksim esasınca pay alırlar. Zira gayn sahih nesepli çocukların yarı hisse alması ancak mirascı olarak meşrû çocuk da mevcut ise câridir. Binnetice, koca ölüp 1000 lira bıraksa ve karısı ile gayn sahih nesepli çoouğu kalsa, kadın mülkiyeti seçmiş ise 250 lira alır, gayn sahih nesepli çoculk 750 lira ijktisap eder.

Hayatta kalan eșin evlâtlikla içtimaı, kkaide olarak meşrû çocukla içtimar gibidir. Fakat evlâd edinmeden evvel yapılan resmî senetle evlâtlığın hissesi meşrû çocuk hissesinden azaltılımış veya kanunen mirascı olamayacağı kabul edilmiş ise, taksim ona göre yapilir.

445 ve 446 .ncı maddeler intifa hakkııın irada çevrilmesinden ve teminattan bahsediyor: Hayatta kalan es, intifa hakkının senevi irad şeklinde verilmesini isteyebilir. Bu halde tereke mallarn rakabe mirasctlarının zilyedliğinde kalacağından, kanun îrad isteyenin diğer mirascilardan teminat isteyeceğini kabul etmiștir. Ancak teminatın istenebilmesi, hayatta kalan ve irad istemiş olan eşin hakkının tehlikede bulunmasınm ispatma bağlıdır. Yani hayatta kalan eș mücerret irad talebi ile birlikde teminat da talep edemez Md: $445 / 2$.

12 Intifa hakkı şahsi olduğundan ve kanunda akside kabul edilmemiş bulundugundan intifa hakkma tevariis edenin ölümï ile sakıt olur, terekesine dahil olmaz.

${ }^{13}$ M. K. Md: $453 / 4$.

${ }^{14}$ Mirasçı nasbı vasiyet veya miras mukavelesi ile olur: 463; 495.

15 Eşin mahfuz hissesi aşılmış olur ve eş müruruzaman (M. K. Md: 513) müddeti içinde tenkis dâvâsı açmamış ise, tasarruf nisabunı aşan tereke de mansup mirasçıya ait olur. 
Md: 445/2, hayatta kalan eş tekrar evlenir, yahut diğer miras. clarm, yani kendisi ile içtima eden rakabe mirascilarının hakları tehlikeye düşerse, bu mirasctların eşden teminat istemeye haklı oldukların beyan ediyor. Bu madde hükmü, hayatta kalan eşin intifa hakkmı irada tahvil etmemiş olduğu halde kabili tatbiktir; zira bu halde üzerinde intifa hakkı olan tereke malları eşin zilyetliğin. de bulunur ve diğer mirascilarm hakları tehlikeye düșebilir. Mücerret tekrar evlenmeyi kanun teminat sebebi saymıștır. Zira bu halde intifa hakkına sahip hayatta kalan eşin zilyet bulunduğu malların bu eșin yeni koca veya karısının tesiri ile istismar olunabileceği farz edilmiştir $\mathrm{ki}$, isabetsiz sayılmaz.

\section{VII - Madde 447 (Evlâtlığın mirascılı̆̆ı)}

Evlâtlığın mirascilığina dâir hüküme 257 inci maddede de tesaduif olunur. Her iki maddenin tefsiri yapılacaktır.

Evlâtlik evlât edinenin kanunî mirascisı olup, aynen meşrû çocuk gibi hisse alır. Gaym sahih nesepli çocukla içtima etse ikili birli taksim kaidesi câri olur.

Evlâd edinmeden evvel yapılan resmî senetle evlâtlı̆̆ın miras hakkı azaltılabileceği gibi, tamamen de kaldırılabilir ${ }^{16}$ Evlâtlı̆̆ın meşrû veya nesebi gayrı sahih füruu evlâd edinene halefiyet suretiyle mirasc1 olur Md: 447/1. olamaz ${ }^{17}$.

Evlâtlığın evlâtlı̆̆ı halefiyet suretiyle evlâd edinene mirascı

Evlâd edinen ve hısımları evlâdlığın kanunî mirascısı olamaz ise de, mansup mirascisı olabilir ve bu sıfatla evlâd edinen şahıs cvlâdlı̆̆ın hakiki ana babasından daha fazla pay da alabilir ${ }^{18}$.

Evlâlığın evlâd edinenin kanunî mirascısı olması, hakiki ana babasından kanunî mirascılığını kaldırmaz Md: 257. Evliler tarafından müștereken evlâd edinilmiş olan kimsenin izâfi ana babası

to Şakir Berki "Mcdenî Hukuk, Ikinci Baskı, 1969, sa: 188 .

${ }^{17}$ Evlâd edinme halefiyet suretiyle mirasçılığa mahal vermedił̧inden, bir şahsıın meşrủ füruunun evlâtlığı da evlâd edinen kimsenin usulünden halefiyet yolu ile miras alamaz.

${ }_{18}$ Bir șahıs ana babasını ve 1000 lira tereke ile taasrruf nisabının tamamın. da evlâd edineni mansup mirascı olarak bıraksa, ana babadan her biri kanunî mirasçı olarak 250 ve evlâd edinen mansup mirasçı olarak 500 Iira alır. 
jle hakiki ana babası bir uçak kazasında ölmüş̧ olsalar, evlâtlık dönt kişiden ayrı ayn meşrû füru olarak miras alır.

Evlâtlığ̣n evlâd edinenden kanunen mirascı olabilmesi mirasın açıldığı zaman evlâtlık münasebetinin mevcudiyetine bağlıdır. Zira evlâd edinmenin ref'i istikbale âit bütün neticelere şâmildir ${ }^{19}$.

\section{VIII - Madde : 448 (Hazinenin Mirascilığı)}

Murisin dört dereceden hiç mirascısı ve eși bulunmaz ve terekesinin tamamı mirascı nasbı veya muayyen mal vasiyeti ile bașkasına intikal ettirilmemiş ise, terekeye kanunî mirascı sıfatıyle ${ }^{20}$ Devlet el koyar. Devlet, mahfuz hisseli mirascı olmadiğndan, muris, terekenin tamamını başkalarına intikal ettirebilir. Bu halde devlet terekeden bir şey alamaz. Terekenin ciiz'ü tasarruf edilmiş ise, tasarruf edilmemiş olan kısım Devlete intikal eder.

Tïrkiyede ölen yabancı veya öldüğii zaman tâbiiyeti belli olmayan (heimatlos) ise, terekenin hangi devlete ait olacağ Devletler Ơzel Hukuku prensiplerine göre tâyin edilir.

Murisin yalnız dördüncü derecedeki mirascrları varsa Devlet bütuin terekenin rakabesine sahip olur, bu derecedeki usul intifa mirascısı olur; büyük ana babaların ana babaları veya kardeșleri

"yoksa, verâset tamamen Devlete aittir. Daha uzak derecedeki usul murisin vefatmda hayatta olsa bile intifa hakkı mirascısı olarak terekeden hiç bir fayda sağlayamaz ${ }^{21}$.

Bir şahsm yalnız gayn sahih nesepli füruu olsa, bütün miras buna geçer, Devlet taksime gelemez. Yani gayn sahih nesepli çocuğun mirasdaaki payının meşrû çocuğun yarı hissesi nispetinde ol-

19 M. K. Md: $258 / 2$.

20 Devletin kanunî mirascılı̆̆ıı ile sair kanunî mirasçılar arasındaki fark, Hazinenin tereke borçlarından ancak eline geçenle mesul olması, diğerlerinin bütiun mamelekleriyle mes'uliyetidir. Bundan başka, Devlet, mahrumiyet, iskat ve mirasdan feragat suretiyle, mirascılık sıfatını zâyi ede. mez; diğer mirasçlar bu yollardan biri ile mirascılık vasfindan mahrum olurlar.

21 Isviçre ve onu takip eden Türk Medenî Kanununun bu sistemi verâsetde adâlet esasına bâriz șekilde aykırıdır. Zira aynı kanunlara göre, bir kimse dedesinin dedesinden, hatta bunların daha uzaklara gidebilen usuländen, füru sıfatıyle mirascı olduğu halde, bütüin usulüin her fürudan mirascilığı kabul edilmemiştir. ki keyfiyet bizce mantıka aykırı olduğu gibi, her iki kanunun kan esasma göre kabul ettiği mirascluk sistemini de tatmin edici değildir. 
duğu dermeyan edilerek, terekenin ikili birli taksim esasinca $2 / 3$ üne Devlet el koymak hakkına sahip değildir.

Murisin hayatta kalan eşinden başka mirascısı olmasa bütün tercke buna âit olur; keza Devlet mirasa gelemez, eș mutlak butlanla bâtıl bir evlenme ile bağlı olsa bile hüküm ayndır. Zira butlan kararına kadar mutlak butlanla dahi bâtıl olan her evlilik sahih evliliğin bütün hükümlerini doğurur ${ }^{22}$. Binnetice mutlak butlanla malûl evlenme akdedenlerden biri, butlan kararı verilmeden evvel ölse ${ }^{23}$ diğer eş ona mirasct olur.

\section{§ 2. ÖLÜME BAĞLI TASARRUFLAR}

\section{I - Md : 449 - 450 (Tasarrufa ehliyet)}

15 yaşın bitiren ve temyiz kudretine sahip olan kimse kanunun tayin ettiği hudut ${ }^{24}$ ve şekillere ${ }^{25}$ riayet etmek şartı ile vasiyet suretiyle mallarnda tasarruf edebilir. Miras mukavelesi yapabilmek için rüşde ${ }^{20}$ erișmiş olmak lâzumdır.

\section{II - Md-451 : (Bâtıl tasarruflar)}

Rızayı fesada uğratan sebepler altında yapılmış olan vasiyet iptali muciptir ${ }^{27}$ Ancak vasiyeti yapan hata, hileye vâkıf olmasina veya tehdit veya cebrin tesirinden kurtulduğu andan itibaren bir sene içinde bu vasiyetten rücu etmemiş ise, vasiyete karşı iptal dâvâsı açlamaz. Tasarrufu yapan kimsenin tasarruf konusunda veya musaleyhin şahsunda hatâ işlediği bâriz bulunur ve hakiki maksadının ne olduğu anlaşlabilinse, tasarruf tashih edilir, yani ona göre icra olunur.

${ }^{22}$ Türk M. K. Md: 124/2. (tSV. M. K. Md: 129).

${ }^{23}$ Dâva esnasında eșlerden birisinin ölmesi ile evlilik esısen zail olacağından butlan davâsına devama da lïzum yoktur. M. K. Md: 114/1). Ancak alâkalılar butlana hüküm aldırabilirler.

${ }^{24}$ Yani mahfuz hisse tecavüz edilmeyecek, veya ahlâka, kanuna âdâba aykırı maksad için yapılmayacaktır. Burada kayd edelim ki bu sonuncu halde vasiyet keenlemyekûn (hükümsüz) olup, iptal dâvâsı açılmasa bile, sclâhiyetli mahkeme tarafindan tenfiz edilemez: meselả eroin vasiyetinde, mer'ayı vasiyetde ilh... hal böyledir.

25 478-488 inci maddelerin izahına bakmız.

${ }^{26}$ Rüş̧đün üç çeșidi de muteberdir.

${ }^{27}$ M.K. Md: $99 / 2$. 


\section{III - Md-452-454 : (Tasarruf nisabi)}

Islâm miras hukukunda tasarruf nisabı daima terekenin üçte biri idi. Mahfuz hisseye göre değişsmezdi. Medenî Kanunda, 453 üncü maddedeki mahfuz hisselere göre değişir. Islâm hukukunda her mirascı mahfuz hisseye sahip iken, Medenî Kanunun 453 üncü maddesi; yalnız füruu, ana babayı, kardeşleri ve hayatta kalan eși mahfuz hisseli mirascı olarak kabul etmis, diğer hısımları kanunî mirascı saydığı halde, onlar lehine mahfuz hisse tanımamış olmakla bunlarn mirasdaki mukadderatını, murisin iradesine, hattâ keyfine tâbi kılmıștır. Filhakika muris, mahfuż hisseli kanunî miracsı bulunmadığı takdirde bütün terekeyi sebep zikretmeksizin başkasına devrederek kanunen mixascı olan, fakat mahfuz hisseli olmayan mirasciları mirasdan uzaklaştırabilir Md: 452/2.

553 ünoï madde, mahfuz hisse miktarm tespit ediyor: füruun mahfuz hissesi miras hakkının ${ }^{28}$ dörtte üçii, baba, ana için yarısı, kardeşlerin her biri için dörtte biri, eș için kanunî mirasclarla içtimal halinde mirasdan mülkkiyet hakkı olan kısmın tamamı, mirasda müstakil ise, terekenin yarısıdrr. Bu miktarlar haricinde kalan tereke kısmı tasarruf nisabıdır. Murisin çeşitli mahfuz hisseli mirasclar içtima etmiş ise, her birinin mahfuz hissesi toplanip bütün tereke kıymetinden çıkarlddktan sonra kalan miktar tasarruf nisabıdır: Hayatta kalan eşle füru içtima etmiş ve tereke 1000 lira olsa, munis ancak bu esasa göre yapılan hesab gereğince terekeden 187,5 lirayı tasarruf edebilecektir. Bu miktar tecavüz edilmisse, her mirascl tecavüzün kendi mahfuz hissesine isabet eden kısmına münhasır olmak üzere tenkis dâvâss ${ }^{29}$ açmaya haklı olur.

Tasarruf nisabl, 454/2 deki borçlar ve masraflar terekeden tenzil edildikten sonra hesap edilir, yani aktif terekeden, sâfi tereke üzerinden hesaplanır. Keza ölüme bağlı olmayan tenkise tâbi teberrular ${ }^{30}$ da tasarruf nisabının hesabı için terekeye ilâve edilir. Sigortalar, mirasın açıldığı andaki kıymetleri ile terekeye dahil edilir Md: 456.

\footnotetext{
${ }^{28}$ Miras hakkl, mirasc1 mirasda müstakil ise ve terekede tasarruf yoksa terekenin tamamidir.

${ }^{29}$ Md: 502 .

$30 \mathrm{Md}: 507$.
} 


\section{IV - Md. 457.460 (Mirasdan iskat)}

Mahfuz hisseli mirasci 457 inci maddedeki fiillerden birini işlediği takdirde, mûris tarafindan ölüme bağh tasarrufla mirasdan iskat edilebilir.

1. Cezaî iskat denilen bu iskatın kısmî olamayacağı 458 inci maddede "... iskat olunan kimse terekeden hisse talep edemez." denilmekle açıkca teyid olunmaktadır.

Iskat edilenin hissesi kaide olarak tasarruf nisabına dahildir. Muris bu hisseyi ölüme bağlı tasarrufla dilediğine devredebilir. Fakat etmemiş veya kısmen etmis ise, hissenin tamamı veya bakiyesi, müteveffanın kanunî mirasclarma geser; ancak iskat edilenin fürusunun mahfuz hissesi ${ }^{31}$ kanunen bunlara ait olur. Bakiye füruun mahfuz hissesi kadar veya daha az olsa, murisin diger, yani iskat edilen ile birlikde taksime iștirak edecek olan kanunî mirascuları bir şey alamazlar.

Iskat anoak murisin ölüme bağlı tasarrufu ve iskat sebebinin zikredilmiş olması șartryla mutebendir. Iskat edilen iskatın haksızlığına ítiraz ettiği takdirde, iskat sebebínin mevcudiyetini ispat iskattan istifade edecek olan mirascrya ${ }^{32}$ yahut iskat edilenin hissesinin kendisine vasiyet edilen şahsa ${ }^{33}$ aittir. Zira iskatın iptaliyle bunlarm menfaati tehlikeye girmektedir.

Sebep beyan edilmemiş veya beyyine ikame edilmemiş ise, müteveffanın iskat arzusunun bir hatâdan sâdır olduğu açıkca anlaşlamiyorsa, iskat yine muteberdir; ancak bu halde iskat mahfuz hisseye şâmil olmaz. 459/2 deki bu hükümle kanun cezaî iskatın kısmî olamayacağı esasını istisnaya tâbi tutmuștur.

2. Md. 460 (Aciz sebebiyle iskat) :

Bu iskat ancak borcunu ödemekten âciz olduğu iskat tasarru. fu anında sâbit füru hakkında câridir ${ }^{34}$ ve yalnız mahfuz hissenin

${ }^{31}$ Md: 458.

32 Bu mirascı hem murisin iskat edilenle içtima eden mirascısı, hem iskat edilenin füruu olabilir.

${ }^{33}$ Iskat edilen hissenin mahfuz hisseden fazla kusmı muris tarafindan muayyen mal vasiyetleri ile tasarruf edjlebileceł̆gi gibi, mansup mirascihk suretiyle de tasarrufa konu olabilir.

${ }^{34}$ Aciz sebebi ile iskat âdetâ füruun alacakhlırından mal kaçırmak gibiđìr. Hakkında daha bir çok tenkitler yapılabilir. Biz yalnız kanun hükmü üzerinde duruyoruz. 
yarısı üzerinde mûteberdir. İskat harici kalan mahfuz hissenin yarısını muris (iskat eden) iskat edilen fürutun mevcut çocuklarına veya doğacak olan çocuklarına tahsis etmesi şarttır.

Aciz sebebiyle iskat da ölüme bağh tasarrufla mümkündür. Keza sebebin yani borç ödemekten aczin tasarruf anında mevcudiyetinin de zikredilmiş olması șarttır.

Miras açldı̆̆ zaman aciz sebebiyle iskat edilen fürû hakkında aciz vesikasınm hükmü kalmamış yahut aciz vesikasındaki borç, iskat edilen füruun miras hakkının yarısından fazla değilse, iskat edilenin talebi ve keyfiyeti ispat etmesi şartıyle iskat hükümsüz hale getirilebilir.

\section{V - Md. 461-465 (ölüme bağlı tasarrufların çeşitleri)}

Vasiyet ve miras mukavelesi olmak uizere iki çeșit ölüme bağl. tasarruf vardır ${ }^{35}$. Vasiyet de iki çeşittir : Muayyen mal vasiyeti; mirascı nasbina dâir vasiyet; Terekeden araba, ev, mikdan belli para ilh... vasiyet edilmis ise, muayyen mal vasiyeti; iterekenin bir cüz' 'ii ${ }^{36}$ vasiyet edilmişse, mirascı nasbı söz konusudur. Gerek muayyen mal vasiyeti, gerek mirascı nasbı miras mukavelesinin de muhtevası olabilir; yani bu iki çeşit vasiyet, miras mukavelesine de derc edilebilir; aym yapılmaları zaruri değildir.

Murisin vasiyet ve miras mukavelesi ile terekesinde tasarruf, mahfuz hisseli mirasc1 yoksa, terekenin tamamina şâmil olabilir; varsa, ancak tasarruf nisabi dahilinde mûteberdir. Aksi halde tenkis dâvâsı ${ }^{37}$ ile mahfuz hisseyi aşan kısım indirilir.

Vasiyet veya miras mukavelesinde lehine tasarruf yapılana şart veya mükelefiyet yüklenebilir. Bu şart veya mükelefiyetler vasiyet konusu, lehine vasiyet yapilana verildigi tarihten itibaren yerine getirilir. Aksi halde alâkadarlar ${ }^{38}$ bunların yerine getirilmesini istemeye haklıdır. Isteğe rağmen yerine getirilmediği takdirde vasiyet mevzuu terekeye iade olunur.

35 Md: 463; 464.

${ }^{36}$ Çünki terekenin $1 / 2,3 / 4$ ith.. gibi cüzülerinin ölüm zamanında ne olacağı vasiyet yapıldığı zaman tâyin edilemez: Md. 463.

37502 ve 513 üncü maddelerin tefsirine bakınız.

${ }^{38}$ Alâkadar kimse, şart veya mükellefiyetten faydalanacak olan hakiki veya hükmî sahıslarla, vasiyetin iptalinden faydalanacak olan mirascilardır. 
Muayyen mal vasiyetindeki sart veya mïkellefiyet, vasiyet odi. len mal miras açıldı̆̆ı zaman terekede çlkmadiğı taktirde, aksi vasiyette yazılı olmadıkça sâkıt olur Md: 464 .

\section{VI - Md. 465-466 (Vasiyet edilen seyin teslimi ve tenkis)}

Vasiyet edilen şey, miras açıldiğı an ne halde ise o suretle teslim olunur. Ev vasiyet edildiği an yeni, fakat miras açıldığı zaman harap, yahut vasiyet edildiği gün aynî mükellefiyetle takyit edilmiş olmadığı halde, miras açıldığı gün takyid edilmiş ise o halde intikal eder; musaleyhin itiraza hakikı yoktur. Vasiyet edilen şey'in krymetinin artması halinde de, mirascların hak iddia etmek yetkisi yoktur: vasiyet tarihinde jki katlı iken miras açıldığ tarihte ü̧̧ kat $)_{ı}$ hale gelmiş olan evin üçìncii katının degerini mirascılar, lehine vasiyet yaplandan isteyemezler.

Vasiyeti tenfiz memuru, mirasın açıldığı günden, teslim anına kadar lehine vasiyet olunana karşı vekâleti olmadan başkası hesabına tasarruf kaidelerine göre mes'ul olduğu gibi, lehine vasiyet yapılmıs olan kkimse de vasiyet konusunun muhafaza ve bakım masraflarını aynı esaslara göre, tenfiz memuruna borçlu olur.

$466 \mathrm{nnc}$ madde, tereke mevcudumu aşan vasiyetin tenkisinden bahsediyor ise de, böyle vasiyet, aşan nispete münhasır olmak üzere kendiliğinden hükümsïzdür. Vasiyeti tenfiz memuruna yaplan teberrû veya tasarruf nisabı aşılmış ise, tenkis o vakit icab eder.

Vasiyeti ifa mü̈kellefiyeti kendisine tahmil edilen kimse, murisden evvel ölür, yahut lehine yapılan teberruu yahut mirascılığı red ettiği takdinde, veya mirasdan mahrum olursa, vasiyet yine tenfiz olunur.

Kanunî veya mansup mirascı mirası red etse bile, lehine yapılan muayyen mal vasiyetini red etmis saylmaz; zira lehine muayyen mal vasiyet edilen kimse, mirascı değldir; binnetice mirascllik sıfatmı kaybetmesi, muayyen mal vasiyeti lehdarı olarak terekeye karşı alacaklılik sıfatına tesir etmez.

\section{VII - Md. 467472 (Íkame)}

Kanun iki çeşit ikame kabul ediyor : Alelâde, fevkalâde ikame.

Alelâdede, lehine muayyen mal vasiyet edilen veya mirascı nasp edilen kimsenin tasarrufu yapandan evvel ölmesi veya vasi- 
yeti reddi halinde mevzuubahistir. Şu halde bu ikamede musaleyh, tasarrufitan hiç istifade etmek imkânt bulamaz. Bu halde tasarruf iradesinin boşa gitmemesi için tasarrufu yapan, taasrrufdan faydalanacak olan diğer şahıs veya şahısları tâyin eder ve vasiyetten bunlar faydalanır. Md: 467.

Fevkalâde ikamede, lehine tasarruf yaplan şahıs tasarrufdan istifade eder; fakat, öldüği zaman veya ikţisaptan muayyen bir müddet sonra mansup mirasci veya muayyen mal vasiyeti lehdar sifatıyle iktisap etmiş olduğunu namzede devretmeye meoburdur. Demekki, ilk mansup mirascı veya muayyen mal vasiyeti lehdârı, tasarrufdan muayyen bir müiddet faydalandiktan sonra, nazmet denilen șahıs faydalanır. Tasarrufu yapan aynı mükellefiyeti namzede tahmil edemez. Yani mütevali fevkalâde ikame câiz değildir. 